\title{
Ver con el cuerpo, tocar con los ojos. Visualidades hápticas en cartografías fílmicas latinoamericanas contemporáneas
}

\author{
Libro de Depetris Chauvin, I. (2018). Geografías afectivas. Desplazamientos, prácticas \\ espaciales y formas de estar juntos en el cine de Argentina, Chile y Brasil (2002-2017). \\ Pittsburgh: Latin American Research Commons.
}

\section{* Azucena Castro \\ Universidad de Buenos Aires. Facultad de Filosofía y Letras. Instituto de Geografía "Romualdo Ardissone". Buenos Aires, Argentina - Universidad de Estocolmo. Suecia.}

Los entrecruces entre cine latinoamericano, geografía y afectos constituyen el meollo de la discusión y especulación teórica del libro de Irene Depetris Chauvin. Se trata de un estudio que recoge una novedosa serie de prácticas cinematográficas del siglo XXI en Argentina, Chile y Brazil, que conforman mapas afectivos y tensionan el territorio en sus construcciones nacionales. A partir del recorrido de un amplio espectro de películas latinoamericanas estrenadas entre el 2002 y el 2017, el libro aborda las maneras en que este cine contemporáneo traza cartografías alternativas a las rutas del oficialismo y del poder, creando con ello comunidades heterogéneas y mundos compartidos.

El libro de Depetris Chauvin conceptualiza esa sensación corpórea que experimentamos como espectadores cuando una película nos involucra físicamente, como si la imagen fuera una textura o superficie que nos convoca dentro de la pantalla o que sale a nuestro encuentro poniéndonos en relación con los otros y con el mundo desde colores, sombras sonidos y ritmos. Si la imagen geográfica, como advierte Verónica Hollman (2016:524-525), se vale de la visión como autoridad y busca constatar un orden para establecer un modelo, pasada por el tamiz de la práctica cinematográfica que estudia Depetris Chauvin, descentra la visión como el órgano perceptivo dominante desde el paradigma cartesiano y explora nuevos imaginarios geográficos que emergen de las dimensiones afectivas y multisensoriales del paisaje.

Inspirada en el mediometraje Le jeu de l'oie. Une fiction didactique à propos de la cartographie (1980) de Raúl Ruiz, cuyas intuiciones zigzagueantes entrecruzan espacios reales, imaginarios y virtuales, Depetris Chauvin transforma tales intuiciones en un método de lectura. Así, el zigzagueo y el merodeo constituyen en este estudio formas de establecer miradas múltiples y hacer dialogar las películas con los afectos, el espacio, la literatura y la fotografía. Este original acercamiento le permite a la autora examinar cómo la imagen móvil del espacio que registra la práctica fílmica pone en tensión la fijeza de la imagen geográfica registrada por métodos cartográficos. Con fundamento en el giro espacial propuesto por la disciplina geográfica y, en particular, la visión de la geógrafa Doreen Massey, la investigación parte de la idea de espacio como un resultante de las interacciones sociales en permanente cambio. El cine es considerado, por tanto, una práctica espacial con el potencial de intervenir los imaginarios geográficos y de hacer entrar al espectador en el espacio de la pantalla para generar afectos y formas de comunidad.

Apoyándose en la idea de "conceptos viajeros" de la teórica cultural Mieke Bal, entendidos como prácticas que desplazan el objeto, Depetris Chauvin transporta los conceptos de paisaje, mapa e itinerario del campo geográfico a la práctica fílmica. Este ejercicio intelectual emplea como punto de partida teórico la idea de "cartografía fílmica" propuesta por la poeta Gabriela Mistral en las primeras décadas del siglo $\mathrm{XX}$, apuntando al potencial cartográfico del cine para ofrecer "paisajes vivientes y sensibles" (Depetris Chauvin, 2019:11). Esta novedosa recuperación del vínculo entre cine, afectos y paisaje móvil desde la poeta chilena, permiten a la 
autora pensar el cine como "cartografía encarnada" (Depetris Chauvin, 2019:9), en tanto que registra huellas, ecos y reflejos de luces que dan cuenta de la vitalidad de los lugares.

Hilando la perspectiva cinematográfica de Mistral con el giro afectivo en las humanidades y en las ciencias sociales y, en particular, la teoría de los afectos de Spinoza, el trabajo se propone poner de manifiesto "fuerzas e intensidades que van más allá del sujeto individual" (Depetris Chauvin, 2019:12). La perspectiva afectiva implica observar intimidades, cuerpos, articulaciones entre cuerpos y espacios y colectividades que desafían la centralidad del sujeto humano en la producción del espacio. Traspasando la perspectiva afectivocorpórea a la imagen cinematográfica, la autora arma una plataforma de lectura para abordar la textura y el sonido en las imágenes como una materialidad física.

En este estudio la imagen cinematográfica es entendida como superficie física que traza recorridos, despierta emociones y genera experiencias somáticas. La propuesta innovadora radica no solo en poner de relieve el potencial de la imagen para pensar el espacio, sino también en instigar la reflexión acerca de cómo la imagen cinematográfica nos permite tocar con los ojos y mirar con el cuerpo. La idea de "visualidad háptica" en el cine que dinamiza este trabajo se fundamenta en la teórica cultural Laura Marks y apunta a funciones multisensoriales de la visión como la de tocar, oír y degustar, que descentran la visión como única fuente del registro de la experiencia sensible. La puesta en diálogo entre la sensorialidad de la imagen fílmica y la idea de "formas comunes" en el arte contemporáneo, inspirada en estudios de la crítica literaria Florencia Garramuño, agrega al marco teórico la idea de comunidad y maneras de estar juntos que desafían el pensamiento dicotómico al integrar afectos impersonales incluyendo lo humano y lo posthumano. Con enfoque en las dinámicas cinematográficas, Depetris Chauvin propone que el cine del siglo XXI configura nuevas cartografías fílmicas en América Latina como formas de acercarse a los otros y de crear lazos afectivos entre cuerpos, materialidades e identidades.
A partir del entretejido de teoría cinematográfica, vocabularios de la estética de los afectos, la geografía cultural y teorías del espacio, se abordan analítica y afectivamente películas de Mariano Llinás, Alicia Scherson, Karim Aïnouz, Marcelo Gomes, Cao Guimarães, José Luis Torres Leiva, Tiziana Panizza, Daniel Casabé, Edgardo Dieleke, Jonathan Perel, Gustavo Fontán, Ignacio Agüero, Raúl Ruiz, Patricio Guzmán y Enrique Ramírez. Este amplio corpus se dispone en capítulos agrupados bajo territorios y trayectos afectivos, conformando seis tipos de cartografías fílmicas que recorren y reformulan cuerpos acuáticos, el sertón, la pampa, islas, ríos y espacios domésticos.

El trayecto denominado Itinerarios dulces y melancólicos acoge el capítulo uno y dos, donde se analiza, por una parte, la ópera prima de Mariano Linás, Balnearios (2002), junto a Viajo porque preciso $y$ volto porque te amo (2009), de Krim Aïnouz y Marcelo Gomes, y Turistas (2009) de Alicia Scherson, por otra parte. A través de un enfoque en las memorias de la infancia y la voz narrativa del falso documental, o mockumentary, el primer capítulo se detiene en explorar cómo en la película de Linás, la imagen del balneario argentino despliega miradas paródicas y melancólicas sobre este espacio de recreación familiar cuyo declive marca la decadencia del país industrial. Una lectura sobre cómo el humor y la parodia subvierten la cartografía oficial de las urbanizaciones y actualizan desde el afecto el imaginario turístico argentino en torno a los enclaves vacacionales. En el segundo capítulo, Depetris Chauvin aborda las geografías íntimas del (des)amor en la película de Aïnouz y Gomes, que recorre el sertão nordestino brasilero, y en la de Scherson, desarrollada en la región de Maule, en el centro chileno. Este abordaje pone de manifiesto cómo las historias de abandono y desamor se mezclan con narrativas de viaje por espacios naturales que reformulan espacios emblemáticos en la historia nacional al enfocarlos desde lo íntimo de la experiencia afectiva. El minucioso análisis nos permite comprender cómo el cine contemporáneo construye una percepción háptica a través de colores y formas que aparecen fuera de foco, tornando porosa la división interior y exterior, imagen y realidad, así como naturaleza y sujeto que la contempla. 
La sección Tierras en trance alberga los capítulos tres y cuatro, donde la autora aborda el documental de viaje Sertão de Acrílico Azul Piscina (2004) de Karim Aïnouz y Marcelo Gomes, como nueva escritura afectiva del desierto sobre el sertão, y los documentales Tres semanas después (2010) de Jorge Luis Torres Leiva y Tierra en movimiento (2014) de Tiziana Panizza, como escrituras sísmicas sobre las geografías del desastre en Chile que elaboran el duelo y la pérdida.

Esa sección, centrada en la tierra, da paso a la condición de insularidad que guía la reflexión en los Estados insulares, sección que traza un recorrido en los capítulos cinco y seis, abordando los acercamientos fílmicos a la Isla de Pascua y las Islas Malvinas. El mismo nos lleva por lo que la autora llama "etno-cartografía" (Depetris Chauvin, 2019:101) en el documental Tierra sola (2014), sobre la cárcel en la remota isla chilena y su relación con el Estado chileno, y por el travelogue y el trabajo del duelo en el documental La forma exacta de las islas (2012), de Daniel Casabé y Edgardo Dieleke, donde las Malvinas se construyen desde la imaginación a partir del archivo de imágenes de la guerra. Se trata de un recorrido analítico nutrido del pensamiento de la insularidad de Deleuze y Guattari desarrollado en la obra La Isla desierta, que nos permite apreciar la relación entre los espacios reales y virtuales como "exploración de la relación cambiante entre el yo y el otro, entre la naturaleza y la cultura" (Depetris Chauvin, 2019:104).

Por su parte, la sección de Geografías sensoriales abraza los capítulos siete y ocho que se dedican a la exploración del potencial sensible de los métodos cartográficos registrados por la práctica fílmica. La reflexión en el capítulo siete se centra en la tríada fílmica de Gustavo Fontán, La orilla que se abisma (2008), El rostro (2013) y El limonero real (2016), a partir de lo que la autora llama "realismo sensorial" (Depetris Chauvin, 2019:127) que vincula expresiones literarias y fílmicas en torno al río. Esta trayectoria aúna la poesía de Juan L. Ortiz con el cine fílmico de Fontán y explora las potencialidades sensoriales y texturales de la imagen, más que su valor referencial para comunicar las "reverberaciones de lo viviente" (Depetris Chauvin, 2019:130). El capítulo ocho reflexiona sobre Andarilho (2007) de
Cao Guimarães, como poética del desplazamiento por el nordeste de Minas Gerais que altera los planos objetivos y subjetivos a través de procedimientos que resaltan lo sensorial, disolviendo los límites de objetos y personajes.

En la sección de Geografías espectrales, el libro recorre los capítulos nueve y diez que abordan la espectralidad en lugares de la memoria y en paisajes acuáticos. El acercamiento analítico a la obra de los cineastas chilenos Raúl Ruiz (Cofralandes, 2002) y Patricio Guzmán (Nostalgia de la luz, 2010) pone de manifiesto un giro espacial en el documental, presentando inscripciones sensibles de la memoria de la dictadura chilena y de los restos de desaparecidos y exiliados en el paisaje en mapeos de la melancolía. Con respecto a los imaginarios hídricos, el capítulo diez nos lleva a un recorrido sumergido por una serie de películas contemporáneas que ponen de relieve "sentidos contradictorios del agua como fuente de vida, epicentro de culturas, pero también cementerios, tanto para las víctimas de la dictadura como para grupos indígenas" (Depetris Chauvin, 2019:172).

Finalmente, bajo la sección final titulada La agencia del mapeo o de cómo vivir juntos, la autora relaciona la práctica del cineasta con la del cartógrafo a través de la idea del "impulso del mapeo" en el cine, tomada de Teresa de Castro (en Depetris Chauvin, 2019:193), que implica un estímulo del cine para ensayar diversas formas de dar a ver el paisaje. En el capítulo once, Depetris Chauvin ofrece un análisis de varias producciones de Jonathan Perel que pone de relieve cómo el minimalismo narrativo y el cine en series de este cineasta aúnan la práctica cinematográfica a la cartográfica. Finalmente, en el capítulo doce el estudio se enfoca en pasajes y espacios intermedios entre la arquitectura urbana y la práctica fílmica, a partir del documental El otro día (2012) de Ignacio Agüero y resalta la formación de "microcosmos domésticos" en Santiago de Chile (Depertis Chauvin, 2019:205), que articulan miradas a las periferias y encuentros fortuitos como maneras de canalizar los flujos afectivos de lo social.

A lo largo del minucioso y detallado recorrido analítico por las seis secciones del estudio, la autora sitúa las prácticas geográficas y los modos del 
afecto en el cine como vías de acceso a cuestiones culturales, sociales y políticas. Pensar la geografía y sus métodos no es privativo del cine como producción cultural. En ese sentido, este estudio dialoga con otras investigaciones que abordan la imagen geográfica y la práctica cartográfica en la literatura y el arte visual. ${ }^{1}$

El recorrido fílmico-afectivo que propone Depetris Chauvin tiene dos inflexiones clave para la disciplina de la geografía. Una es discutida por la autora y se relaciona con la propuesta de que la práctica fílmica es una forma de pensamiento que permite reflexionar sobre las prácticas cartográficas como dispositivos de poder, a la vez que las "geografías cinemáticas" que conforman estas prácticas están insertas en las dinámicas de producción y consumo del espacio social con las que producen pensamiento sobre el espacio y generan respuestas afectivas (Depertis Chauvin, 2019:218). La otra inflexión que observo es que este estudio ofrece un bosquejo de una práctica geográfica posthumana a partir de análisis de cine. Si el campo emergente de la geografía posthumana que vienen desarrollando los estudios de Ruth Panelli (2010) y Juanita Sundberg (2013) plantea revalorizar la materialidad multiespecie del territorio, más allá del ser humano como centro de la producción de conocimiento, Depetris Chauvin pone de relieve cómo la dimensión afectiva del cine produce lazos entre el mundo humano y las comunidades no-humanas de plantas, animales, agua y tierra que redimensionan la perspectiva geográfica acerca de la producción de espacio como práctica compartida con la agencialidad de otros seres con los que cohabitamos el planeta. En efecto, la reflexión final del libro propone un posible camino de exploración para el campo de la geografía afectiva relacionado con la producción reciente de películas regionales que activan la experiencia sensorial y corpórea del medioambiente como respuesta ética en el contexto urgente de las devastadoras crisis ecológicas en la región.

Las cartografías fílmicas que mapea esta original propuesta de Depetris Chauvin ponen de manifiesto

1 En este contexto, podemos mencionar el estudio de Robert Tally (2014) que interrelaciona literatura y cartografía y de Harriet Hawkins (2014) que aborda la geografía en intersección con la práctica artística visual. el potencial del cine como arte del espacio que traza nuevos recorridos, desestabiliza itinerarios fijos e imagina nuevos pasajes en la experiencia del espacio y en su producción desde el plano afectivo. Así, este libro nos sitúa ante la imagen cinematográfica y nos pide tocarla, palparla y olerla apelando a una visualidad háptica: ver con el cuerpo y tocar con los ojos como forma de experimentar el espacio y de pensar maneras alternativas de hacer comunidades desde la práctica fílmica.

\section{Bibliografía}

» Hawkins, H. (2014). For Creative Geographies. Geography, Visual Arts and the Making of World. Nueva York, Londres: Routledge.

» Hollman, V. (2016). Ante las imágenes: los desafíos del giro visual para la geografía. Geousp - Espaço e Tempo, 20(3), 518-535.

»Panelli, R. (2010). More-Than-Human Social Geographies: Posthuman and Other Possibilities. Progress in Human Geography, 34(1), 79-87.

» Sundberg J. (2014). Decolonizing Posthumanist geographies. Cultural geographies, 21(1), 33-47.

» Tally, R.T. (Ed.) (2014). Literary Cartographies: Spatiality, Representation, and Narrative. Nueva York: Palgrave Macmillan.

\section{Azucena Castro / azugreen33@gmail.com}

Doctora en lenguas románticas con especialización en español y teoría literaria (Universidad de Estocolmo), Máster en literatura-cultura-medios (Universidad de Lund), profesora en lengua y literatura inglesa (Universidad Nacional de Córdoba). Actualmente es posdoctoranda del Instituto de Geografía "Romualdo Ardissone" de la Facultad de Filosofía y Letras de la Universidad de Buenos Aires. También integra el Grupo de Estudio "Cultura, Naturaleza, Territorio" del Instituto de Geografía de la UBA y el equipo de investigación "Imaginarios medioambientales en narrativas del Antropoceno: Tensiones y perspectivas 2018/2022" financiado por SECyT, Universidad Nacional de Córdoba. Su investigación aborda cuestiones medioambientales en la literatura y la cultura visual en América Latina. 